\title{
Transformação urbana vista "de baixo": clubes de futebol de várzea e estratégias de articulação para conquista de seus campos de jogo (1960-1979)
}

\author{
Raphael Rajão Ribeiro* \\ raprajao@gmail.com
}

\begin{abstract}
Resumo
O presente artigo tem por objetivo examinar as articulações estabelecidas entre as estratégias utilizadas pelos clubes de futebol de várzea para manter a posse de seus campos de jogo e o contexto de transformação urbana vivenciado por Belo Horizonte durante as décadas de 1960 e 1970. Ao investigar as mudanças pelas quais a cidade passava a partir da perspectiva dos grupos ligados a essa prática de lazer popular, o texto espera apontar possibilidades de aproximação entre a História Urbana e a História Social, demonstrando maneiras de pensar as modificações do tecido urbano por meio da atuação dos "de baixo". Compartilha-se a compreensão de que essas coletividades dialogam com processos diversos que implicam a reconfiguração do espaço, tais como normativas legais, políticas públicas e atuação de setores imobiliários. Ao desenvolverem relações muitas vezes de clientela com forças políticas ou econômicas, podiam intervir nas decisões sobre os usos dos terrenos, de forma que sua permanência em certas áreas da capital mineira não pode ser explicada como mero resultado do acaso ou do desejo governamental. Em suas disputas cotidianas, tais agremiações se depararam com questões concernentes ao associativismo comunitário, aos constrangimentos de um estado burocrático-autoritário e às dificuldades impostas por uma metropolização acelerada e sem planejamento. Para a produção do texto foram utilizadas fontes orais, registro de imprensa e documentação oficial do município e da federação de futebol local.
\end{abstract}

\section{Palavras-chave}

História Urbana; História Social; Futebol Amador; Associativismo; Belo Horizonte

Urban transformation seen "from below": "Futebol de várzea" clubs and the articulation's strategies to conquer their playing fields (1960-1979)

\begin{abstract}
The present article aims to examine the articulations between the strategies used by the "futebol de varzea" clubs to maintain the possession of their playing fields and the context of urban transformations experienced by Belo Horizonte during the 1960's and the 1970's. Investigating the changes for which the city passed by through the perspective of the groups connected with the practice of popular leisure, the text hopes to indicate possibilities of approximation between Urban History and Social History, demonstrating ways to think the modifications of urban fabric by means of the actions of those from below. We share the comprehension that this communities dialog with multiples process which implicated in the spaces' reconfigurations, such as legal regulations, public policies and the action of real estate sectors. Developing relations quite often paternalistics with the political or economical forces, they could intervene in the decisions about the terrains' uses, in a way that their stay in certain areas of the city couldn't be explained only by coincidence or governmental desire. In their day by day's disputes, these organizations faced questions concerning the communal associativism, the constraints of a bureaucratic and authoritarian state and the difficulties imposed by an accelerated and unplanned metropolisation. For the production of this text had been used oral narratives, press records and official documentation from the municipality and the local football federation.
\end{abstract}

\section{Keywords}

Urban History; Social History; Amateur Football; Associativism; Belo Horizonte

*Doutorando em História, Política e Bens Culturais no Centro de Pesquisa e Documentação de História Contemporânea do Brasil da Fundação Getúlio Vargas (CPDOC/FGV). 


\section{Introdução}

A cidade constitui-se como uma das principais questões das ciências sociais no século XX, em grande medida por decorrência de rápidos processos de migração de populações rurais vivenciados naquele momento, o que mudou a divisão dos percentuais de habitantes naqueles dois meios, o qual passou a pender em seu favor. Alçada a um dos maiores problemas da humanidade, tornara-se alvo de ramo do conhecimento que reivindicava a hegemonia sobre a realização de intervenções em sua dinâmica e no seu espaço: o urbanismo.

Ciência cuja constituição remete ao século anterior, esse campo do saber defendia uma visão da cidade como organismo passível de intervenção planejada que direcionaria o seu desenvolvimento, o que, para alguns autores, indica aproximações entre o urbanismo e as concepções utópicas (HALL, 1988 e RYKWERT, 2004). Nessa perspectiva, seria possível interferir no comportamento dos habitantes por meio da definição de formas e fluxos do tecido urbano, conformando, assim, os modos de vida naquele território.

O exame da realidade vivida aponta para uma imprevisibilidade muito maior do que a imaginada pelas utopias urbanísticas. Para além de todos os constrangimentos pensados de conformação do espaço, estabelecimento de normas legais, implantação de mecanismos de controle, há um sem número de grupos sociais e indivíduos que são capazes de se apropriar dessas estruturas de modo a ressignificá-las em favor de seus objetivos e desejos.

Nessa medida, pensar a História Urbana conjugada às estratégias de análise da História Social, em busca da compreensão das formas pelas quais grupos chamados subalternos lidam com os constrangimentos impostos pelo ordenamento urbano em prol da afirmação de seu uso da cidade, pode ser interessante alternativa para se aventarem outros movimentos de transformação do tecido urbano.

É partindo dessa premissa que o presente texto propõe examinar a atuação dos clubes de futebol amador de Belo Horizonte na disputa por espaço para o estabelecimento de seus campos durante as décadas de 1960 e 1970. Essa abordagem dialoga com um debate da história dos movimentos sociais no Brasil que, por muito tempo, considerou que os grupos populares não haviam conseguido constituir-se como força política relevante. Grande número de estudos buscou demonstrar como os coletivos trabalhadores e suas instâncias de representação, os sindicatos, foram recorrentemente subjugados pelas estruturas de estado, pelos poderes econômicos ou pelos partidos de esquerda ${ }^{1}$.

Tal visão pessimista das possibilidades de atuação das camadas populares estava fortemente informada pelos desdobramentos e aprofundamentos do regime autoritário no país. Naquele contexto, o controle sobre sindicatos e demais entidades parecia incontornável, sendo que tal tendência de tutela constante reproduziria permanência histórica que teria se verificado em toda a trajetória do movimento operário nacional.

Seria o fortalecimento dos movimentos sociais e de trabalhadores, no final dos anos 1970, já no momento de enfraquecimento do regime autoritário, bem como a renovação no campo das ciências sociais, com toda a crítica às leituras de cunho estruturalista, que permitiria a emergência de novas interpretações acerca da atuação das classes operárias na história brasileira. Especial-

\footnotetext{
${ }^{1}$ Boa parte dessa produção esteve vinculada à Escola Sociológica Paulista, sendo os estudos de Leôncio Rodrigues os que mais claramente sintetizaram essa visão. Cf. PAOLI; SADER \& TELLES, 1983. Mesmo autores como Francisco Weffort, celebrado como um dos que primeiro perceberam a novidade da atuação autônoma das classes trabalhadoras, corroborou com a visão da debilidade do operariado nacional em seus textos sobre o populismo brasileiro dos anos 1950. Cf. WEFFORT, 1973.
} 
mente voltada para a Primeira República, período marcado pela atuação anarco-sindicalista, em especial na cidade de São Paulo, bem como para o passado recente, com a atuação do Novo Sindicalismo e de articulações comunitárias na capital paulista e na região do $\mathrm{ABC}$, toda uma produção ganhou corpo nos programas de pós -graduação em História e em Ciências Sociais, reposicionando o papel desempenhado por operários e outros subalternos na condução de suas próprias trajetórias e nos conflitos em torno da conquista de direitos políticos e sociais ${ }^{2}$.

Ao dialogar com perspectivas emergentes como a História Social, em especial a vertente inglesa, e os estudos de viés pós-estruturalista, essa produção atribuiu novos sentidos à atuação dos grupos subalternos. Em especial, tais trabalhos têm em comum a valorização da agência desses atores sociais e sua incorporação como forças transformadoras relevantes para a compreensão da realidade dos períodos pesquisados.

Em que pese a renovação proposta por essa produção, ela acabava recorrendo a momentos específicos da história nacional, a saber, Primeira República e período da transição democrática, por entender que as possibilidades de atuação dos grupos populares estaria restrita a conjunturas específicas nas quais eles se tornaram capazes de agir de forma autônoma em relação a instâncias de controle como seriam os órgãos de Estado, os partidos políticos e os sindicatos oficiais.

Ao tratar de forma mais detida o debate sobre movimentos sociais de base popular, observa-se uma grande concentração dessa produção entre finais da década de 1970 e toda a década de 1980. Especialmente impactada pela efervescência que marcou a transição democrática, esses estudos enfatizaram a novidade representada pela organização dos grupos subalternos, em especial os de base comunitária, e a sua autonomia de atuação ante os organismos de governo.

Como indica bibliografia mais recente, essa temática dos movimentos sociais vivenciou uma forte queda de interesse nos anos 1990, com a mudança do foco para outras formas de mobilização, vide organizações não governamentais (ONGs) e mecanismos institucionais de participação popular. Estudos contemporâneos retomam a problematização dos anos 1980, especialmente à luz de contradições apresentadas pelos novos mecanismos de articulação. Contudo, a tendência de valorização da experiência no período de distensão do regime autoritário, em finais da década de 1970, persiste $^{3}$.

Ao discutir algumas alternativas de atuação de grupos populares ligados ao futebol de várzea de Belo Horizonte nos anos 1960 e 1970, em especial, durante a vigência da Ditadura Militar, pretende-se identificar as margens de atuação de coletivos subalternos nesse momento de aprofundamento dos mecanismos de controle no país. Eles ajudam a reconhecer formas de organização social que atravessaram esse período. Serão destacados três casos de articulação dos clubes e de seus dirigentes para a manutenção de campos de jogo próprios, os quais se teriam dado em resposta às condições decorrentes de transformações nacionais e locais, específicas desse período. Como se verá a seguir, diversas eram as contradições desse momento, as quais não passavam despercebidas pelos atores sociais e eram por eles mobilizadas.

\footnotetext{
${ }^{2}$ Para citar alguns desses trabalhos, com relação à Primeira República destacam-se CHALHOUB, 1986; RAGO, 1985 e DECCA, 1987. Já no que se refere ao Novo Sindicalismo e aos movimentos sociais urbanos, são exemplos SADER, 1988 e PAOLI, 1987.

${ }^{3}$ Corroboram essa perspectiva trabalhos como DOIMO, 1995; HOUSTON, 2013 e LAVALLE, CASTELLO e BISCHIR, 2011.
} 
O exame desses casos compõe parte das reflexões de estudo mais abrangente que está sendo desenvolvido em nível de doutorado e que tem por objetivo investigar as relações entre o futebol de várzea e o fenômeno de metropolização de Belo Horizonte. Para tanto, é mobilizada uma diversidade de fontes que vai desde relatos orais, passando por registros da imprensa local, até documentação oficial do município e da Federação Mineira de Futebol, à qual os clubes eram filiados. No caso das entrevistas aqui utilizadas, elas foram coletadas no âmbito de projeto que vem sendo desenvolvido pela Fundação Municipal de Cultura da cidade em parceria com a Secretaria Municipal de Esportes e Lazer, que se denomina "Inventário do Futebol Amador em Belo Horizonte". Essa ação tem por objetivo principal o registro da prática como patrimônio imaterial do município. Os depoentes são figuras com longa atuação nas entidades, sejam dirigentes ainda ativos ou pessoas com passagem reconhecida na agremiação que participaram de entrevistas temáticas centradas na trajetória histórica dos clubes esportivos. Esses três casos fazem parte de um universo maior que totaliza quarenta e seis associações pesquisadas.

\section{Esporte Clube Santa Maria: associativismo e relações políticas locais}

No final dos anos 1950, iniciaram-se diversas intervenções urbanas com vistas à transformação da zona sul de Belo Horizonte, a qual seria convertida no principal eixo de expansão das moradias das classes altas e médias locais. O curso do Córrego do Leitão, situado na região do bairro Coração de Jesus, antiga Colônia Agrícola Afonso Pena, seria alvo, nas duas décadas seguintes, de várias obras que implicaram a contenção de suas águas, com a formação de uma barragem, em sua canalização e na conseguinte construção da Avenida Prudente de Morais, que conectou a região à área central da capital mineira.
Esse processo implicou a valorização dos terrenos daquela região, vista como uma das últimas possibilidades de expansão de Belo Horizonte no sentido sul. Nessa medida, ao longo dos anos 1970 e 1980, uma série de empreendimentos imobiliários deu origem a bairros para as classes altas e médias.

Uma das primeiras medidas para a realização das obras de canalização do Córrego do Leitão, as quais se estenderam do final da década de 1950 até o início da de 1970, foi a remoção da população que habitava a várzea formada na parte inicial do curso d'água. Naquele lugar, já se expandia ocupação que dera origem ao que é hoje a Vila Barragem Santa Lúcia. Partindo do baixio, onde o barro se acumulava, ela se estendia morro acima, até os limites da BR3, estrada que levava ao Rio de Janeiro, na parte alta. Aproveitando-se da argila que se formava no fundo da várzea, uma cerâmica se instalara no local, empregando boa parte dos moradores dali, era a Cerâmica Santa Maria.

A retirada dos moradores foi seguida de medida de realocação, com a construção de conjunto residencial na parte mais alta da região, às margens do que viria a ser a Avenida Raja Gabaglia, eixo importante da expansão da cidade para região sudoeste. Como informou o relatório apresentado pelo Prefeito Amintas de Barros para o ano de 1960:

Por ser necessariamente lenta a marcha do desfavelamento, procuramos normas objetivas de ação, plantando obras nos setores mais necessitados.

No transcurso de 1960, o Departamento construiu no Conjunto Residencial Santa Maria mais de 52 apartamentos, que se acham ocupados por famílias antes faveladas.

Deve ser assinalado que naquêle Conjunto estão também quase concluídos mais dois blocos residenciais, reunindo um total de 32 apartamentos. No referido local foram iniciados e concluidos trabalhos de urbanização, tais como: Rêde pluvial, calçamento poliédrico num total de 12.000 metros quadrados, com mais 
de 2.000 metros de meio-fio, e inúmeras vias de acesso ${ }^{4}$.

O trecho anterior faz parte dos relatórios apresentados anualmente pelos prefeitos à câmara municipal. Nesse documento, o mandatário local resumia as realizações do período. Principal peça de síntese da atuação da gestão, esse registro buscava construir um sentido para o conjunto de medidas de governo. As ações em questão foram conduzidas pelo Departamento Municipal de Habitações e Bairros Populares, órgão criado para conduzir a política de desfavelamento em Belo Horizonte. Sua atuação era financiada pela taxa de habitação popular, criada nos anos 1950 e que correspondia a $3 \%$ sobre o valor dos loteamentos aprovados e dos prédios a serem construídos. O projeto do novo local de moradia procurava recriar os modos de vida dos habitantes, com a substituição das casas por prédios de pequeno porte, desenhados pelo arquiteto Sylvio Vasconcellos, com vistas a integrar aquela população aos modos de vida urbano-industriais (OLIVEIRA, 2014, p. 99 $-108)$.

A exemplo do que ocorria na área antes ocupada pelos moradores transferidos para o Conjunto Santa Maria, tão logo começaram a se instalar ali, duas entidades associativas foram criadas: o Centro de Defesa Coletiva do Conjunto Santa Maria e o Esporte Clube Santa Maria. Ambas, reproduziam formas de organização que já eram vivenciadas na Vila Barragem Santa Lúcia. Sobre o comitê, Vicente de Souza Prados, mais conhecido como Pardal, morador do lugar desde sua criação, comentou em entrevista:

Antigamente não falava associação não, falava assim: Centro de Defesa Coletiva do Bairro Santa Maria. Então, nesse Centro de Defesa Coletiva tinha seis homens que eram os cabeças desse negócio ai. Era o Oscar, Carlão, Antônio Grande, Aprígio, tem um outro que eu não me recordo o nome... e Seu Geraldo (inaudivel) ${ }^{5}$.

Ambas as instituições foram criadas ainda no final da década de 1950, quando os primeiros moradores se instalavam no local. Em sua primeira década de existência, o Esporte Clube Santa Maria dedicou-se à participação em jogos amistosos e excursões, promovendo, dentre outros, os tradicionais festivais em comemoração à passagem de seu aniversário. Foi só no final da década de 1960 que se tomaram as providências necessárias à sua filiação ao Departamento de Futebol Amador da Federação Mineira de Futebol, o que permitiria que pudesse participar do campeonato promovido pela entidade.

Na mesma época em que o Santa Maria preparava sua documentação para ingressar no circuito competitivo do futebol amador de Belo Horizonte, o Diário da Tarde - DT, jornal ligado aos Diários Associados, fundado por Assis Chateaubriand, publicava a série de reportagens "O seu Alô!, Alô! vai aos bairros". Periódico vespertino, de perfil mais popular em relação ao coirmão Estado de Minas, o DT se dedicava, principalmente, à cobertura de temas esportivos, policiais e do cotidiano da capital mineira. Reconhecido difusor da várzea local, mantinha, também, famosa coluna voltada à participação dos leitores, a "Alô!, Alô!", que recebia reclamações por telefone sobre problemas do dia a dia. Como um desdobramento da seção, o repórter João de Paulo Pires passou, no ano de 1968, a visitar diferentes

\footnotetext{
${ }^{4}$ Relatório de 1960 apresentado à egrégia Câmara Municipal pelo prefeito Amintas de Barros. Fevereiro de 1961, p. 114. Acervo Arquivo Público da Cidade de Belo Horizonte.

${ }^{5}$ Entrevista de Modestino da Silva Araújo, Sebastião “Tião" Fernandes da Silva e Vicente "Pardal” de Souza Prados concedida a Raphael Rajão Ribeiro em 5 de junho de 2016.
} 
regiões da cidade, para coletar in loco as queixas dos habitantes.

As reportagens publicadas a cada sábado eram reveladoras da manutenção do associativismo de bairro, mesmo em um contexto de Ditadura e vigilância constante dos movimentos sociais. Como forma de levar ao leitor as reivindicações que marcavam o cotidiano de cada parte da cidade, o jornalista recorria aos líderes comunitários locais, reconhecidos como interlocutores autorizados para apresentar as demandas do lugar. Nessa perspectiva, evidencia-se um sem número de entidades representativas, a exemplo de diversos comitês prómelhoramentos, tais como os dos bairros Santa Môni$\mathrm{ca}^{6}$, Santa Maria Gorete ${ }^{7}$, Santa Inês ${ }^{8}$, Monsenhor Mes$\operatorname{sias}^{9}$ e Vila Melo Viana ${ }^{10}$. Além de Sociedades de Amigos, próprias de bairros mais tradicionais como Serra ${ }^{11}$ e Floresta ${ }^{12}$, bem como Associações de Moradores ${ }^{13}$ e uma sui generis "Associação do Pessoal do Bairro Marajó", região cuja coluna publicada sobre ela tinha o sugestivo subtítulo "Marajó é o fim do mundo"14. Outras instâncias de articulação eram citadas, tal como a Associação de Pais e Mestres do Grupo Escolar Júlia Lopes de Almeida, no bairro Saudade ${ }^{15}$.

Ainda sobre a vida associativa nos bairros, a coluna evidenciava as mediações de alguns grupos influentes, tais como a Igreja Católica, apontando para a presença de padres que ajudavam na organização das associações de moradores, como era o caso do jovem pároco francês Xavier Berthou, que auxiliava as atividades da Associação de Moradores do Horto ${ }^{16}$, ou ainda, do Padre Luiz Alarcon, que assumira a presidência do Comitê Pró-melhoramentos do Bairro Santa Môni$\mathrm{ca}^{17}$. Outra instituição marcante era o $\operatorname{SESI}^{18}$, que havia conduzido a organização do Conselho Comunitário "Assis Chateaubriand" do Vale do Jatobá ${ }^{19}$. Na ausência, ou em lugar das representações locais, a coluna costumava recorrer a vereadores ou ex-vereadores reconhecidos como vinculados às regiões ${ }^{20}$.

Assim como por diversos bairros da cidade, o Conjunto Santa Maria contava com sua associação, o Centro de Defesa Coletiva. Dentre seus membros, dois foram diretores do Esporte Clube Santa Maria e, no contexto de formação da agremiação e de conquista de um campo de jogo para a entidade, desempenharam papel importante. Ambos eram funcionários dos correios, como comentou Vicente "Pardal":

Era com ele. Um presidente que teve aqui era Oscar. Oscar Rodrigues... Oscar Miranda Rodrigues, um negócio assim. Esse Oscar, ele era do Correio e era muito ligado a esses políticos e ele trouxe eles para cá para ajudar o time, naquela época ninguém tinha nada não. Ninguém tinha nada. Era tudo carente. O Oscar trabalhava para o correio, o Carlão trabalhava para o correio também. (...) En-

${ }^{6}$ Cf. "O seu Alô!, Alô! vai aos bairros", Diário da Tarde, 4 de maio de 1968, p. 2.

${ }^{7}$ Cf. "O seu Alô!, Alô! vai aos bairros", Diário da Tarde, 11 de maio de 1968, p. 2.

${ }^{8} \mathrm{Cf}$. "Santa Inês agradece pesquisa do "Alô!, Alò!(sic)"”, Diário da Tarde, 6 de junho de 1968, p. 2.

${ }^{9}$ Cf. "O seu Alô!, Alô! vai aos bairros”, Diário da Tarde, 29 de junho de 1968, p. 2.

${ }^{10}$ Esse último comitê, passava então a se chamar Associação Comunitária Melo Viana. Cf. "O seu Alô!, Alô! vai aos bairros", Diário da Tarde, 20 de julho de 1968, p. 2.

${ }^{11}$ Cf. "A Serra agora está unida", Diário da Tarde, 13 de maio de 1968, p. 2.

${ }^{12}$ Cf. "O seu Alô!, Alô! vai aos bairros", Diário da Tarde, 15 de junho de 1968, p. 2.

${ }^{13}$ Cf. "O seu Alô!, Alô! vai aos bairros", Diário da Tarde, 17 de agosto de 1968, p. 2.

${ }^{14}$ Cf. "O seu Alô!, Alô! vai aos bairros", Diário da Tarde, $1^{\circ}$ de junho de 1968, p. 2.

${ }^{15}$ Cf. "O seu Alô!, Alô! vai aos bairros”, Diário da Tarde, 7 de junho de 1968, p. 2.

${ }^{16}$ Cf. "O seu Alô!, Alô! vai aos bairros", Diário da Tarde, 24 de agosto de 1968, p. 2.

${ }^{17}$ Cf. "O seu Alô!, Alô! vai aos bairros”, Diário da Tarde, 4 de maio de 1968, p. 2.

${ }^{18}$ Sobre a atuação do SESI, vale destacar o clássico texto de WEINSTEIN, 2000, que aponta para a atuação dessa instituição no associativismo de bairro, bem como na organização do esporte popular.

${ }^{19}$ Cf. "O seu Alô!, Alô! vai aos bairros”, Diário da Tarde, 10 de agosto de 1968, p. 2.

${ }^{20} \mathrm{Cf}$. "O seu Alô!, Alô! vai aos bairros", Diário da Tarde, 18 de maio de 1968, p. 2; "O seu Alô!, Alô! vai aos bairros", Diário da Tarde, 22 de junho de 1968, p. 2 e "O seu Alô!, Alô! vai aos bairros", Diário da Tarde, 27 de julho de 1968, p. 2 
tão eles pegaram esses caras maiores, que era do conhecimento deles e foi para ajudar e foram ajudando, pegando conhecimento com nós. O Santa Maria, ele teve, e sempre tem, uma grande diretoria, uns pessoal que batalhava mesmo, à época, como se diz, não tinha muita leitura não, mas tinha conhecimento. ${ }^{21}$

Em 1969, quando o Santa Maria entrou com seu pedido de filiação na Federação Mineira de Futebol, como vice-presidentes da agremiação constavam os nomes de Oscar Rodrigues Sobrinho, funcionário dos Correios e Telégrafos, que também era diretor de esportes, e de Carlos Lourenço, funcionário público federal, que acumulava a função de secretário geral da entida$\mathrm{de}^{22}$. Como destacou Pardal, a presença dos dois membros do Centro de Defesa Coletiva do Conjunto Santa Maria teria sido importante para a agremiação, já que eles mantinham relações com figuras políticas da épo$\mathrm{ca}^{23}$. Personagem especialmente destacado, nesse contexto, seria Jorge Ferraz, deputado estadual, proprietário de terras na região ${ }^{24}$. Tendo iniciado sua carreira política em 1947 como vereador, teve longa atuação, até 1986, quando, na condição de deputado federal, abandonou a carreira política. Teve em seu filho, Paulo Eduardo Ferraz, o sucessor político, o qual ocupou a cadeira de deputado estadual entre os anos 1979 e $1986^{25}$.

Uma das bases eleitorais de Jorge Ferraz era a região onde se localizava o Conjunto Santa Maria. Nessa perspectiva, os integrantes do Esporte Clube Santa Maria teriam boa articulação com o político e dono de terras, o que teria garantido dois importantes benefícios à agremiação, os quais foram informados no processo de filiação da entidade à Federação Mineira de Futebol:

O Espote(sic) Club Santa Maria, fundado em 9/9/1969, nesta Capital, com sua sede e praça de esporte, de sua propriedade, no Conjunto Residencial Santa Maria, Bairro Coração de Jesus. Inicialmente com um total de 76 (setenta e seis) socios, sendo 70 (setenta) socios atletas e 6 (seis) contribuintes, o patrimonio do ESPORTE CLUBE SANTA MARIA, atualmente esta com um patrimônio no valor de ncr\$ 600,00 (seiscentos cruzados novos) mais ou menos ${ }^{26}$.

Segundo a declaração apresentada, o clube, que iniciara suas atividades em 1958, mas que se registrara apenas em 1969, seria proprietário de sua sede, bem como do campo, ali denominado praça de esportes, caso raro no meio varzeano, já que, na maior parte das vezes, a ocupação do espaço de jogo era a título precário e as dependências sociais costumavam ser alugadas. Segundo relatos dos antigos moradores do lugar, a sede teria sido doada diretamente por Jorge Ferraz, enquanto o espaço de jogo teria sido destinado pela Prefeitura. Esse último, até hoje, pertence à agremiação. O primeiro teria sido vendido ao Governo do Estado, para instalação de uma unidade da Companhia de Águas e Saneamento do Estado de Minas Gerais, sendo que o valor pago ainda se encontra sub judice, já que há um impasse entre os membros da entidade e os herdeiros do político, que reivindicam a propriedade do terreno ${ }^{27}$.

\footnotetext{
${ }^{21}$ Entrevista de Modestino da Silva Araújo, Sebastião “Tião” Fernandes da Silva e Vicente "Pardal” de Souza Prados concedida a Raphael Rajão Ribeiro em 5 de junho de 2016.

${ }^{22}$ Cf. Pasta do Santa Maria no Departamento de Futebol Amador da Capital. Acervo do Esporte Clube Santa Maria.

${ }^{23}$ Interessantes paralelos sobre a aproximação entre o futebol amador e as redes de clientelismo político tratam-se do artigo FONTES, 2014, que aborda a mobilização dessas relações na São Paulo de meados do século XX e da tese SPPAGIARI, 2015 que explora essas relações no contexto atual da zona leste de São Paulo.

${ }^{24}$ Cf. Entrevista de Modestino da Silva Araújo, Sebastião "Tião" Fernandes da Silva e Vicente "Pardal" de Souza Prados concedida a Raphael Rajão Ribeiro em 5 de junho de 2016.

${ }^{25}$ Cf. Verbete FERRAZ, Jorge. Dicionário Biográfico. Centro de Pesquisa e Documentação de História Contemporânea do Brasil - CPDOC/FGV. Acessado em 5 de fevereiro de 2018. Disponível em: http://www.fgv.br/cpdoc/acervo/dicionarios/verbete-biografico/ferraz-jorge

${ }^{26}$ Pasta do Santa Maria no Departamento de Futebol Amador da Capital. Acervo do Esporte Clube Santa Maria.

${ }^{27}$ Cf. Entrevista de Modestino da Silva Araújo, Sebastião "Tião" Fernandes da Silva e Vicente "Pardal" de Souza Prados concedida a Raphael Rajão Ribeiro em 5 de junho de 2016.
} 
Carlos Lourenço seguiu como membro da diretoria da agremiação por vários anos. Em festival realizado em 1978, em comemoração aos 20 anos de fundação do Santa Maria, aparecia entre os homenageados especiais, junto de outros ex-presidentes da agremiação ${ }^{28}$.

A articulação do Esporte Clube Santa Maria com forças políticas locais e o poder público municipal, intermediada por seus dirigentes que também eram integrantes do Centro de Defesa Coletiva do Conjunto Santa Maria, aproxima-se de modelos de relações de trocas de favores examinadas em casos como o de bairros periféricos de São Paulo no momento do intervalo democrático $^{29}$. A persistência dessa forma de atuação dos grupos populares, assim como a manutenção de um sem número de associações de bairro, que eram uma das bases dessas redes políticas, aponta para continuidades de formas de organização nos bairros que atravessaram o período ditatorial no país e, mais uma vez, foram mobilizadas quando da emergência dos novos movimentos urbanos do final dos anos 1970.

\section{Reunidos Esporte Clube: expansão urbana e criação de espaços de recreação}

Em maio de 1968, o jornal Diário da Tarde repercutiu a publicação de pesquisa promovida pelo Centro de Desenvolvimento e Planejamento Regional CEDEPLAR da Faculdade de Ciências Econômicas da UFMG. Segundo a pesquisa, Belo Horizonte já consolidava região metropolitana que englobava 10 municípios. O detalhado estudo debruçou-se sobre diversos aspectos da área, de sua demografia e de sua economia. O material subsidiaria o Serviço de Planejamento Habi- tacional e Urbanísticos do Governo Federal a desenvolver diretrizes para a Grande BH, conforme convênio já firmado com a Prefeitura local ${ }^{30}$.

Dentre os dados apresentados pelo estudo, destacava-se, por exemplo, a percepção de que, naquele momento, cabia à construção civil e à indústria o emprego do maior número de trabalhadores, com 50 mil e 46 mil pessoas, enquanto comércio e serviços ocupavam, respectivamente, 29 e 14 mil indivíduos ${ }^{31}$. Segundo a pesquisa, uma preocupação era o baixo crescimento do emprego na indústria, em comparação ao da população:

Se considerarmos, diz o documento, que a taxa de aumento de emprêgo industrial, conjuntamente em $\mathrm{BH}$ e Contagem $(4,8 \%)$, veremos que esta ainda é inferior à taxa de crescimento da população em idade produtiva. Enquanto a população em idade produtiva de $\mathrm{BH}$ cresceu, no periodo, de 166.294 pessoas, o aumento do emprego no setor industrial foi apenas 9.719, ou seja: $5,8 \%$ da população citada $^{32}$.

Sob os impactos de um fluxo considerável de novos habitantes vindos do interior, em decorrência do êxodo rural, a baixa absorção de mão de obra agravava as condições de moradia da população local. Como ressaltava o estudo:

Em 1964, o censo indicou 79 favelas, habitadas por 119.799 pessoas, correspondendo a 25.076 domicílios. No mesmo ano o número de favelados representava $14,75 \%$ da população da cidade. (...) Em 1955, o número de favelados era de 36.432, correspondendo a $9.343 \mathrm{do}$ micílios. $O$ aumento de moradias, no intervalo dos dois levantamentos foi de $168 \%$ e o da população foi de $229 \%$, bem superior à expansão demográfica de $\mathrm{BH}$ como um todo. ${ }^{33}$

\footnotetext{
${ }^{28}$ Cf. Pasta do Santa Maria no Departamento de Futebol Amador da Capital. Acervo do Esporte Clube Santa Maria.

${ }^{29}$ Cf. Duarte e Fontes, 2004. Nesse artigo, os pesquisadores examinam ampla rede formada por Adhemar de Barros e Jânio Quadros nos bairros da Mooca e de São Miguel Paulista, a qual incluía associações de bairros e clubes de futebol amador.

${ }^{30} \mathrm{Cf}$. Belo Horizonte de cabeça para baixo, Diário da Tarde, 14 de maio de 1968, p. 3.

${ }^{31}$ Cf. APESAR DE TUDO, BH VAI CRESCENDO, Diário da Tarde, 15 de maio de 1968, p. 3.

${ }^{32}$ APESAR DE TUDO, BH VAI CRESCENDO, Diário da Tarde, 15 de maio de 1968, p. 3.

${ }^{33} \mathrm{BH}$ cresce, aumentam as favelas, Diário da Tarde, 20 de maio de 1968, p. 3.
} 
O quadro se mostrava ainda mais dramático, quando se considerava a situação dos bairros que eram criados no contexto da expansão urbana da capital mineira. Como ficou evidenciado na coluna "Alô!, Alô!" ou na série "O seu Alô!, Alô! vai aos bairros", inúmeros eram os povoamentos que se davam em áreas sem os mínimos requisitos de infraestrutura, ressentido-se de calçamento, iluminação, abastecimento de água, saneamento, coleta de lixo e transporte público. Tais condições de vida da população foram examinadas, conforme repercutiu o Diário da Tarde:

Segundo dados da SAGMACS e repetidos na pesquisa dirigida pelo professor Paulo Roberto Haddad, quase metade da população de BH vivia em condições insatisfatórias em 1958. A percentagem correspondente aos moradores das unidades incluidas no tipo "popular precário" em que se somam os moradores das unidades tipo "popular inferior". Tôda a zona norte e oeste da Cidade e a periféria (sic) das zonas leste e sul concentram esse tipo de habitação. ${ }^{34}$

Não apenas as condições de moradia eram um problema no perfil de ocupação dos novos bairros, frutos da rápida expansão. A falta de espaços comuns também se destacava:

A falta de planejamento na urbanização da cidade, segundo o documento, provoca a "triste consequência" da escassez de áreas verdes. Temos 73 praças e 33 jardins apenas, a maioria sem plantações. ${ }^{35}$

Além de praças e jardins, havia a percepção da necessidade de outros espaços que pudessem ser utilizados pelas coletividades das ocupações que surgiam. Nesse sentido, dois projetos foram propostos na Câmara Municipal de Belo Horizonte para contornar a situação. O vereador Gil Nunes, que recorrentemente apare- cia na série "O seu Alô!, Alô! vai aos bairros" apresentando as demandas de bairros da região leste, formulou projeto de lei que previa a "reserva de área de terreno de $1000 \mathrm{~m}^{2}$ mais ou menos, no centro de cada Bairro ou Vila, para servir como ponto de recreação para os moradores da região ${ }^{36 "}$. Ainda segundo previsão da lei do vereador Gil Nunes, "a área desapropriada será reservada exclusivamente para locação, pela Prefeitura, a parques de diversões, circos e outras espécies de diversão ${ }^{37 \%}$.

Outro projeto de lei que ganhava as páginas dos jornais era de autoria do vereador João Batista Cardoso e objetivava autorizar a Prefeitura a construir pequenos estádios, destinados, exclusivamente, à prática do futebol amador. Segundo justificativa apresentada pelo político quando do encaminhamento de sua proposição:

O simples fornecimento de material esportivo é política pouco recomendável. (...)

Ajuda substancial, entendemos, é extamente (sic) a de formar o patrimonio das associações, garantir-lhes meios de desenvolvimentos, financeiro e técnico.

Isto só é possivel com a construção de "estadinhos", com razoáveis condições de utilização, conforto e segurança tais construções seriam disseminadas pelos Bairros e Vilas. (...)

(...) Nestas condições, evitar-se-ia o esfacelamento do futebol varzeano, cada ves (sic) mais empobrecido com a falta de campos, tomado pelo crescimentos (sic) da "urbs",38.

Partindo da contraposição entre o crescimento urbano e a indisponibilidade de áreas para a manutenção dos campos das agremiações populares, o vereador apontava as limitações de uma política de esportes que se contentava apenas em realizar a oferta de equipamentos esportivos aos clubes, tais como bolas e jogos

\footnotetext{
${ }^{34}$ Falta casa nesta área, Diário da Tarde, 20 de maio de 1968, p. 3.

${ }^{35}$ Falta casa nesta área, Diário da Tarde, 20 de maio de 1968, p. 3.

${ }^{36}$ Fundo Câmara Municipal de Belo Horizonte - DR.01.02.09-9269, p. 1a. Acervo Arquivo Público da Cidade de Belo Horizonte.

${ }^{37}$ Fundo Câmara Municipal de Belo Horizonte - DR.01.02.09-9269, p. 1a. Acervo Arquivo Público da Cidade de Belo Horizonte.

${ }^{38}$ Fundo Câmara Municipal de Belo Horizonte - DR.01.02.09-9276, p. 2. Acervo Arquivo Público da Cidade de Belo Horizonte.
} 
de camisas. Para ele, uma das questões fundamentais a se resolver era a constituição de patrimônio entre essas associações atléticas, com a doação de terrenos. Vale destacar que tal política de transferência de lotes a instituições dessa natureza foi praticada com regularidade pela Prefeitura em relação às entidades vinculadas ao esporte profissional. Nos anos 1940, por exemplo, Atlético, Cruzeiro e América receberam da Prefeitura de Belo Horizonte terrenos para exploração comercial na região da Pampulha, então em franca expansão. A concessão desses lotes visava ao aumento do patrimônio dos clubes, não tendo sido utilizados para construção de equipamentos relacionados à sua atividade primordial. (LAGE, 2016).

De acordo com o Diário da Tarde, o projeto foi recebido com entusiasmo pelo meio varzeano, que esperava sua rápida aprovação e a imediata construção dos ditos "estadinhos" 39. Segundo avaliação sarcástica de um dos vereadores,

A Idéia é excelente. O povo precisa de pão e circo para não se revoltar contra o estado de coisas reinantes, contra as injustiças sociais, contra as dificuldades da vida. Se a Prefeitura não pode dar "pão", que dê pelo menos o "circo". 40

Tal declaração aponta para um dos inúmeros motivos apresentados como relevantes para o desenvolvimento da iniciativa. Sendo que predominava a afirmação de que o crescimento urbano afetava diretamente a manutenção dos espaços esportivos destinados à prática do futebol amador, já tão tradicional na cidade.

Ambos os projetos se arrastaram até o ano de 1970, quando foram aprovados e sancionados pelo executivo municipal. Segundo noticiado pelo Diário da
Tarde, a proposta de Gil Nunes de reserva de áreas viabilizaria política que a Prefeitura não conseguia efetivar:

Tôda área residencial precisaria ter a sua zona verde, para recreação. A própria Prefeitura exige isso, quando alguém pede autorização para fazer novo loteamento. Acontece, no entanto, que é exigência geralmente não cumprida e, por isso, bairros e vilas não têm, hoje, um lugar onde a população possa ter o seu divertimento. ${ }^{41}$

Já a proposta dos "estadinhos" de João Batista Cardoso foi saudada como possibilidade de sobrevivência da prática do futebol de várzea, "ameaçada que estava pela falta de campos" ${ }^{\prime 4}$.

A mobilização do Reunidos Esporte Clube é reveladora da trajetória de aplicação dessas duas legislações voltadas para a solução da ausência de áreas de convívio comum nos bairros populares. $\mathrm{O}$ caso também evidencia de que forma as agremiações varzeanas e suas diretorias se articulavam com a regulação urbanística, desenvolvendo relações dúbias com os poderes públicos e com a especulação imobiliária.

Fundado em 1946, o Reunidos é dissidência de outra agremiação do mesmo bairro, o Alvorada Futebol Clube, criado 10 anos antes. Sediados na Vila Oeste, mantinham seus campos de jogo lado a lado, em terreno pertencente ao Governo do Estado de Minas Gerais, às margens do córrego Tejuco. Nos anos 1940, o local situava-se em povoamento afastado, na região oeste da cidade, com pouca articulação com a área central. Boa parte da sociabilidade de seus moradores restringia-se à própria localidade, sendo essas associações esportivas as principais opções de recreação, com a oferta não só

\footnotetext{
${ }^{39} \mathrm{Cf}$. Os clubes amadores confiam no projeto do estádio, Diário da Tarde, 27 de setembro de 1968, p. 11.

${ }^{40}$ Fundo Câmara Municipal de Belo Horizonte - DR.01.02.09-9276, p. 20. Acervo Arquivo Público da Cidade de Belo Horizonte.

${ }^{41}$ A Prefeitura quer um oásis em cada bairro, Diário da Tarde, 9 de junho de 1970, p. 3.

${ }^{42}$ Os estadinhos vão fazer a várzea nascer outra vez, Diário da Tarde, DT Esportes, 13 de junho de 1970, p. 14.
} 
de jogos, mas também com a promoção de bailes em suas sedes.

Nos anos 1970, com o avanço das obras de estruturação da metrópole que se consolidava, Reunidos e Alvorada tiveram de abandonar o campo que ocupavam, já que ali seria aberta a Via Expressa, avenida de trânsito rápido que conectaria a região central aos municípios situados a oeste de Belo Horizonte. Segundo memória de um antigo morador do lugar, com passagem pelas duas equipes, mais de uma dezena de espaços destinados à prática do futebol desapareceram apenas com essa construção ${ }^{43}$.

Frente a isso, a diretoria do Reunidos passou a se mobilizar para conquistar um novo espaço. A região na qual o time estava sediado, até então vista apenas como área afastada do centro, com a construção da nova via, vinha sendo alvo da especulação imobiliária. Ali atuava o principal empreiteiro da cidade, recorrentemente acusado de grilagem de terras, chamado Antônio Luciano, dono da construtora FAIAL ${ }^{44}$. Segundo relato do ex-presidente da agremiação, Jair Colen Filho, o Lu, à época, atleta do clube:

Aconteceu assim, quando o seu José Bonifácio que era o presidente, lá da Via Expressa, quando ele pediu o Luciano um terreno aqui, o Luciano permitiu que ele construísse um vestiário, que na verdade, a própria FAIAL, que era a empresa do Luciano, construiu um vestiário para o Reunidos. ${ }^{45}$

Lu se refere a um expediente que era mais ou menos recorrente no meio varzeano da cidade, o qual se referia à disponibilização de terrenos por especuladores imobiliários aos clubes de futebol que cumpriam a fun- ção de vigilantes, impedindo que outros grupos viessem a se apropriar do local, por exemplo, para o estabelecimento de um núcleo de moradias. Tal situação, inclusive, foi apontada por João Batista Cardoso em comentário sobre o seu projeto para construção dos "estadinhos":

Á medida que a "urbs" cresce, os terrenos vão sendo valorizados, os campos são tomados pelos proprietários, que os cederam em caracter precario com o fim de evitarem a invasão por favelados. ${ }^{46}$

Ocupar temporariamente terreno pertencente ao reconhecido especulador imobiliário da cidade foi a alternativa encontrada pela direção do Reunidos para manter a atividade do clube e para abrigar outros times que tradicionalmente utilizavam o seu campo. Contudo, como relatou $\mathrm{Lu}$, seria uma brecha legal que começou a se desenhar na década de 1970, que permitiria a manutenção do espaço de jogo da agremiação:

E, com a morte do Luciano, essa herdei-
ra dele é que veio, essa área era... a di-
mensão dela era enorme, vinte e tantos
mil metros quadrados, ela loteou tudo e,
por força de lei, teve de separar a área
institucional, tantos por cento da área, e
acharam por bem, como o Reunidos já
estava aqui deixar essa área institucional
para o Reunidos, mas só foi regularizado
quase que dez anos depois, que o Reuni-
dos permaneceu nessa área até que a
Prefeitura veio e fez o contrato. Aí cor-
reu solto, né? Ninguém tomou conta, nin-
guém invadiu.

Por meio da previsão legal de que todo loteamento deveria reservar áreas de uso comum, o Reunidos foi capaz de manter a utilização do espaço de jogo. A porção do terreno foi doada à Prefeitura, que estabeleceu com a agremiação contrato de permissão de uso.

\footnotetext{
${ }^{43}$ Cf. Entrevista de Nilton “Chapinha” Graciano da Silva concedida a Raphael Rajão Ribeiro em 21 de setembro de 2016.

${ }^{44}$ Dentre os principais críticos de Antônio Luciano e de suas práticas de ocupação dos terrenos estava o jornal O Binômio, dirigido por José Maria Rabelo. Cf. OLIVEIRA, 2010.

${ }^{45}$ Entrevista de Jair "Lu" Colen Filho concedida a Raphael Rajão Ribeiro em 18 de setembro de 2016.

${ }^{46}$ Fundo Câmara Municipal de Belo Horizonte - DR.01.02.09-9276, p. 4. Acervo Arquivo Público da Cidade de Belo Horizonte.

${ }^{47}$ Entrevista de Jair "Lu" Colen Filho concedida a Raphael Rajão Ribeiro em 18 de setembro de 2016.
} 
Ao longo dos anos, algumas benfeitorias foram realizadas, com a construção de novo vestiário e instalação de alambrado.

Esse mesmo artifício seria mobilizado por vários outros clubes de futebol amador de Belo Horizonte, em muitos casos, contando com a mesma parceria com a FAIAL. A presença de Antônio Luciano e de sua construtora na cidade aparecem em diversos relatos acerca da trajetória de outras agremiações varzeanas de Belo Horizonte. $^{48}$

Quanto à lei de construção dos "estadinhos", em 1975, o vereador João Batista Cardoso questionava o descumprimento da previsão, reprovando a atuação do executivo $^{49}$. No mesmo ano, seu colega de Câmara Municipal, Luiz Otávio “Ziza” Valadares fazia um balanço da atuação do prefeito com relação à promessa de realização das obras:

3 - Estadinhos para o futebol amador: Pierucetti prometeu ceder vários estadinhos para clubes de futebol amador, quando eles começaram a perder seus campos, tomados pelos proprietários dos terrenos onde se localizavam. O vereador Luís Otávio Valadares considera risivel o número de estadinhos construidos, diante do grande número de times existentes em Belo Horizonte e que estão morrendo por falta de campo ${ }^{50}$

Efetivamente, nos moldes previstos na legislação, de "estadinhos" para cerca de 10 mil pessoas, nunca houve construção que atendesse às agremiações varzeanas da cidade. Com a transformação das políticas de esportes nos anos 1970, as possibilidades de recursos via, convênio com a Diretoria de Esportes do Governo do Estado nunca se concretizaram de modo a atender ao futebol amador. No novo cenário, o que se viu foi a destinação desses valores ao chamado esporte especializado, com a construção de complexos poliesportivos, alguns deles em lugar antes ocupado por campos. Ao contrário do que se esperava, foi regulamentação pensada para circos e parques de diversão que criou a brecha utilizada não apenas pelo Reunidos, mas por outras entidades do gênero.

\section{Alvorada Futebol Clube: burocratização das políticas de esporte}

A promulgação do Decreto-Lei 3.199, de 14 de abril de 1941, durante o Estado Novo, estabeleceu por quase todo o restante do século XX, a forma de organização das atividades esportivas no Brasil. A configuração desse sistema guarda muitas similaridades com os esforços de estruturação do meio sindical no mesmo período. Em linhas gerais, Meily Linhales apontou como principais efeitos dessa normatização:

A partir dessa perspectiva disciplinar/ corporativa que embasa o Decreto-Lei $n^{\circ} 3.199 / 41$, o esporte brasileiro passou a ser controlado pelo Estado (contra a autonomia); as entidades esportivas, tais como confederações e federações, foram oficializadas (contra a iniciativa privada e de grupos); o sistema esportivo sofreu uma verticalização linear de suas funções (contra o pluralismo); institucionalizou-se o "aparelhamento da ordem", mediante a criação do CND (contra o poder estatutário que regia a organização de várias modalidades esportivas) $e$, finalmente, a "harmonia" $e$ a "disciplina" passaram a ser as palavraschave e de justificativa (contra o conflito). Assim, o Estado introduz, na organização esportiva, as intenções de controle $e$ intervenção que paulatinamente foi construindo para tomar em suas mãos

\footnotetext{
${ }^{48}$ Outros exemplos da participação da FAIAL no processo de disponibilização de terrenos para campos de futebol amador em Belo Horizonte são encontrados nos seguintes depoimentos: Entrevista de Cláudio Henrique "Claudinho" Soares concedida a Raphael Rajão Ribeiro em 19 de agosto de 2016; entrevista de Gemir "Miruca" de Souza e Marcelo de Paula concedida a Raphael Rajão Ribeiro em 24 de junho de 2016 e Entrevista de Jorgeval Costa Lima e Edval Gomes da Rocha concedida a Raphael Rajão Ribeiro em 8 de abril de 2017.

${ }^{49}$ Vereador quer saber se o Prefeito cumpre a lei 1837. Diário da Tarde, Belo Horizonte, 20 de fevereiro de 1975, p. 11.

${ }^{50}$ De como não cumprir, em quatro anos, o prometido. Diário da Tarde, Belo Horizonte, 21 de março de 1975, p. 3.
} 
toda a sociedade brasileira. (LINHALES, 1996, p. 89-90)

Se a exemplo do que ocorrera com a legislação sindical, o intervalo democrático vivenciou esforços de conciliação entre arcabouço normativo autoritário e práticas mais liberais, a emergência da Ditadura Militar implicou a reapropriação das regulamentações estadonovistas em favor da exacerbação do controle estatal (LINHALES, 1996, p. 111-134).

Um dos principais instrumentos desse domínio era o Conselho Nacional de Desportos e, seus braços locais, os Conselhos Regionais. Segundo exigência da legislação, todas as entidades esportivas tinham de manter registros atualizados no órgão, com a retirada anual de alvarás de funcionamento.

Em maio de 1968, o Conselho Regional de Desportos de Minas Gerais empreendeu campanha de regularização dos registros das associações esportivas do estado, o que colocou em polvorosa o meio atlético local. Naquele mesmo momento, terminava mais um campeonato municipal de futebol amador e era hora de as agremiações se inscreverem para a nova edição, com início previsto para o mês seguinte. Segundo cobertura do Diário da Tarde:

Vem dando "pano pra manga" o problema dos clubes amadores que deixaram de tirar o Alvará de Funcionamento, desrespeitando lei do Conselho Nacional de Desportos. O relaxamento de clubes e entidades esta (sic) sendo motivo de apreensão, por que o Conselho Regional de Desportos está cobrando dos clubes desde que êstes existem. O monte (sic) Azul, por exemplo vai ser obrigado a desembolsar, agora, a importância de $\mathrm{NCr} \$ 60$, não se falando em vários outros clubes que deixaram de cumprir a lei na época oportuna. O representante da Associação Atlética Formosa afirmou que não disputara o compeonato (sic) do
$D F A$, se tiver que pagar mais de um alvará.

Depois de uma fase liberal, na qual não se atentava ao correto pagamento dos alvarás anuais pelos times, não físcalizando a sua participação nas competições esportivas, o CRD resolvia apertar o cerco e cobrar retroativamente todas as autorizações de funcionamento. Essa situação implicou o adiamento do campeonato daquele ano, já que muitas agremiações solicitaram prazo adicional para tentar resolver sua situação junto ao órgão regulador ${ }^{51}$. O cenário era de um torneio esvaziado, dadas as dificuldades dos clubes em atenderem aos requisitos. ${ }^{52}$

Cumprindo suas ameaças, o CRD definiu-se pela suspensão das entidades que não regularizaram sua situação. Como informou o Diário da Tarde:

\begin{abstract}
Muitos representantes de clube procuraram, ontem, o Conselho Regional de Desportos, na av. Olegário Maciel, 311, para tentar conseguir o alvará de funcionamento, com medo de suas associações serem fechadas pela Policia, em atendimento ao decreto-lei 5.342. Todos eles voltaram decepcionados, pois o CRD não está disposto a dar o tradicional "jeitinho" e ouviram do secretário José Jonusan que no próximo ano poderão conseguir o alvará, mesmo assim, pagando a multa relativa ao ano anterior ou anteriores, caso o clube não possua o de 1967 também. $^{53}$
\end{abstract}

Utilizando-se de decreto-lei do período do Estado Novo, que regulamentava as atividades do CND, o órgão fiscalizador suspendeu mais de 1.800 clubes naquele ano. Essa intervenção teve impacto direto na condução do campeonato varzeano de 1968, com a desistência de um grande número de times. Com relação à divisão principal, o Diário da Tarde informava que 24 clubes conseguiram inscrever-se, enquanto outros 16 não

\footnotetext{
${ }^{51}$ Cf. Campeonato do DFA começa em julho. Diário da Tarde, 25 de junho de 1968, p. 12.

${ }^{52} \mathrm{Cf}$. Várzea êste ano tem só 15 no campeonato. Diário da Tarde, 5 de junho de 1968, p. 11.

${ }^{53}$ Já são 1.800 os clubes ilegais. Diário da Tarde, 4 de julho de 1968, p. 11.
} 
reuniram condições de participar. Esses últimos não apenas ficaram fora da competição, como corriam o risco de ver suas atividades paralisadas pelo resto do ano. $^{54}$

No contexto de controle e de diversas exigências burocráticas, a criação de um clube capaz de tomar parte nas competições oficiais, bem como sua manutenção não era tarefa simples para os envolvidos com o futebol amador de Belo Horizonte. Nessa perspectiva, a filiação ao Departamento de Futebol Amador da Federação Mineira de Futebol, bem como a regularização junto aos órgãos fiscalizadores do esporte, era um ativo importante a ser preservado pela agremiação e valorizado pelos seus congêneres, que admiravam aqueles que tomavam parte aos torneios oficiais, os quais eram sistematicamente divulgados por veículos de imprensa, em especial Diário da Tarde, reconhecido, à época, como o principal meio de informação dos interessados no futebol varzeano.

Nesse universo de entidades esportivas renomadas, uma das que mais se destacava, seja por sua tradição, seja por sua organização, era o Alvorada Futebol Clube. A agremiação da Vila Oeste fora fundada em 1936 e, desde o início dos anos 1950, participava regularmente das competições promovidas pelo $\mathrm{DFA}^{55}$. Boa parte de seus diretores e atletas era pertencente ao mesmo núcleo familiar que vivia no, então, longínquo bairro $^{56}$. Bem relacionados com os gestores públicos da região, foram capazes de garantir campo em terreno pertencente ao Governo do Estado ${ }^{57}$, além de viabilizar espaço de jogo para o coirmão Reunidos Esporte Clube. Mesmo quando perderam sua área em função da cons- trução de uma fundação de saúde estadual, conquistaram outro local, nas cercanias, onde puderam seguir com suas atividades ${ }^{58}$. Para isso, colaborava a inserção profissional dos dirigentes do clube. Segundo registro da diretoria de 1965, por exemplo, contava com dois funcionários públicos estaduais na condição de presidente e vice-presidente, um vinculado ao Instituto Ezequiel Dias, localizado no bairro vizinho da Gameleira, e outro, lotado no DOPS. ${ }^{59}$

Sobre a inserção de alguns dirigentes dos clubes varzeanos, vale a pena notar tanto no caso do Esporte Clube Santa Maria, quanto no do Alvorada Futebol Clube, que a participação desses indivíduos nas diretorias expressavam mecanismos de distinção social constituídos nessas comunidades periféricas de Belo Horizonte. Não por acaso, figura ocupantes de postos no funcionalismo público, com maior trânsito no meio político, assumiam as funções administrativas das entidades. Suas escolhas para posições de destaque podem ser compreendidas tanto pelos benefícios que teriam possibilidades de trazer às associações, como pela transposição de reconhecimento alcançado junto aos vizinhos, dada a valorização de sua condição profissional no contexto de bairros de forte traço popular, de extração socioeconômica mais pobre.

Com a construção da Via Expressa, no entanto, não foi mais possível ao Alvorada continuar mantendo seu espaço de jogo na região, para o que se fez necessária articulação de sua diretoria para viabilizar nova alternativa para promoção de suas partidas. A solução encontrada foi deslocar-se para um bairro ao lado, o Nova Gameleira. Ali já existia um campo pertencente à

\footnotetext{
${ }^{54}$ Interessante notar que da lista dos 24 clubes que conseguiram se manter no campeonato daquele ano, 11 ainda existem até os dias de hoje, quanto aos desistentes, dos 16 apenas 1 segue em atividade. Cf. Terrestre fora do campeonato. Diário da Tarde, 4 de julho de 1968 , p. 11.

${ }^{55} \mathrm{Cf}$. Entrevista de Nilton "Chapinha" Graciano da Silva concedida a Raphael Rajão Ribeiro em 21 de setembro de 2016.

${ }^{56} \mathrm{Cf}$. Entrevista de Wellerson "Beiça” Fabian Januário concedida a Raphael Rajão Ribeiro em 20 de agosto de 2016.

${ }^{57}$ Cf. Pasta do Alvorada no Departamento de Futebol Amador da Capital. Acervo do Alvorada Futebol Clube.

${ }^{58}$ Cf. Entrevista de Nilton "Chapinha" Graciano da Silva concedida a Raphael Rajão Ribeiro em 21 de setembro de 2016.

${ }^{59} \mathrm{Cf}$. Pasta do Alvorada no Departamento de Futebol Amador da Capital. Acervo do Alvorada Futebol Clube.
} 
equipe do Vila Rica, agremiação não filiada ao DFA da FMF. Depois de passar algum tempo mandando suas partidas ali, o clube da Vila Oeste chegou a um entendimento com seu anfitrião, como relatou em entrevista o atual presidente Wellerson Januário, mais conhecido como Beiça:

O Alvorada veio para o Nova Gameleira. Porque a Via Expressa passou, dividiu o campo, e não tinha jeito, não tinha local pro campo. Ai o Alvorada fez uma... uma união com o Vila Rica, que era um time local, que tinha um campo, só que tem que não era registrado, que veio o Alvorada, ou o Vila Rica veio a acabar e se tornar Alvorada. (...) A família Rabelo participava do Alvorada. Mas o Hott pegou a presidência, porque? Ele tinha o campo e o Alvorada tinha o nome. Ai ele pegou a presidência, aí juntou o útil ao agradável, o Alexandre [Rabelo] era o vice dele e o Hott era o presidente. ${ }^{60}$

A regularização de um time para ingresso no DFA sempre foi tarefa difícil, inúmeros são os relatos de antigos membros que apontam para os gastos e as diversas etapas burocráticas necessárias para a concretização do processo ${ }^{61}$. No final da década de 1970, quando houve a incorporação do Vila Rica ao Alvorada, a agremiação da Vila Oeste já alcançava reconhecimento no meio varzeano local, tendo-se inclusive sagrado campeã da cidade no ano de 1972 . Nessa perspectiva, o entendimento entre as direções das equipes para a fusão solucionava dois problemas e surgia como estratégia interessante de manutenção das atividades de ambas.

No contexto de crescimento urbano de Belo Horizonte e de maior burocratização do meio atlético local, tanto a posse de um campo, quanto a regularização do registro junto à Federação Mineira de Futebol e ao Conselho Regional de Esportes eram importantes ativos constituídos pelas agremiações. Conquistá-los, naquele momento, não representava tarefa fácil para grupos po- pulares, cada vez mais distanciados dos centros de tomada de decisão. Nessa perspectiva, a fusão, por meio da troca dessas vantagens mantidas pelos clubes, era estratégia de sobrevivência e continuidade do desenvolvimento da prática a qual se dedicavam havia décadas, como era o caso do antigo time da Vila Oeste.

Com o passar do tempo, o Alvorada foi criando maior identidade com o bairro Nova Gameleira, reconhecido local de moradia de policiais militares de baixa patente. Ainda assim, membros das famílias da Vila Oeste acompanham, mesmo que de longe, o dia a dia do clube. Os antigos antagonistas, Reunidos e Alvorada, cujos campos eram vizinhos, desde a construção da Via Expressa, migraram em direções opostas. No contexto de uma cidade em transformação, diferentes alternativas de sobrevivência levaram-nos a estabelecer seus espaços de jogo em áreas diversas. Hoje, apenas na lembrança dos mais velhos e na rivalidade que aos poucos vai dissipando-se, sobrevive a memória da história que partilharam durante mais de três décadas.

\section{Considerações finais}

A segunda metade da década de 1960 não marcou apenas o aprofundamento de um regime autoritário no país. No caso de Belo Horizonte, foi também o momento no qual, passada a primeira fase de expansão metropolitana fruto de explosão demográfica na cidade, iniciava-se uma série de obras de estruturação urbana, que impulsionava ainda mais os movimentos de especulação imobiliária e loteamento de novos bairros.

Essa mistura de governo autoritário e demandas públicas e privadas por terras foi especialmente impactante para a prática do futebol de várzea na capital mineira, que via suas margens de atuação em busca de

\footnotetext{
${ }^{60}$ Entrevista de Wellerson "Beiça" Fabian Januário concedida a Raphael Rajão Ribeiro em 20 de agosto de 2016.

${ }^{61}$ Cf. Entrevista de José Pimenta Gomes de Oliveira concedida a Raphael Rajão Ribeiro em 8 de fevereiro de 2017.
} 
alternativas de espaços para manutenção de sua prática ainda mais limitadas.

Os três casos citados são exemplares das possibilidades de ação dos grupos vinculados às agremiações amadoras mesmo em contexto tão desfavorável como o apontado acima. Ajudam a ponderar sobre as estratégias que as camadas populares foram capazes de desenvolver em sua vida cotidiana. Em todas as ocasiões, essa atuação foi tutelada ou submissa a um poder maior, mostrando-se reativa a dificuldades impostas pelos processos de intervenção do Estado e do poder econômico. Mesmo assim, é possível perceber que não fosse a mobilização dos atores vinculados aos clubes, seu destino seria o mesmo de tantos outros que se viram alijados de seus campos e que acabaram por sucumbir, dada a falta de condições materiais de continuidade de suas atividades ${ }^{62}$.

O caso de Santa Maria Esporte Clube evidencia tendências de um associativismo de bairro ainda marcado por relações clientelistas especialmente relacionadas com figuras do poder legislativo, vereadores e deputados estaduais, que tinham em alguns bairros da cidade seus redutos eleitorais. Interessante perceber que, mesmo no contexto da Ditadura Militar, essas relações se mantiveram, ainda que mais vigiadas e controladas. Ao contrário do que muitas vezes a bibliografia sobre o tema deixa entender, quando fala a emergência de movimentos sociais ligados à temática urbana no final da década de 1970, pode-se notar que houve a persistência de articulações em prol de melhorias nas localidades carentes de infraestrutura. Sem menosprezar as inovações do período de distensão do regime autoritário, tal continuidade aponta para experiências pregressas de associativismo comunitário que serviam de referência de luta por melhores condições de vida.

$\mathrm{Na}$ busca por atender às suas clientelas, os vereadores formulavam legislações que pudessem responder às demandas locais, que os mesmos percebiam em sua presença cotidiana pelas regiões, mas que também eram vocalizadas em colunas tais como a "Alô!, Alô!", do Diário da Tarde. Essas normativas eram muitas vezes inócuas, em pouco impedindo o avanço da especulação imobiliária e a forma desordenada como novos loteamentos eram aprovados. Os membros dos clubes varzeanos, em uma relação dúbia, na qual, ao tomarem conta de terrenos nos quais mantinham seus espaços de jogo, atuavam quase como "capangas" de conhecidos grileiros locais, mostravam-se capazes de seguir com suas atividades, ainda que de forma precária ${ }^{63}$. Essa presença nas áreas de futura urbanização, associada a leis quase sempre pouco efetivas, poderiam abrir possibilidades para garantia de permanência mais duradoura, como foi o caso do Reunidos Esporte Clube.

Não bastassem os desafios impostos pela pressão fundiária própria de uma metrópole em expansão, as agremiações ainda precisavam responder às demandas de um estado burocrático-autoritário, que ampliava cada vez mais os mecanismos de tutela e controle das associações. Nessa medida, frente às dificuldades impostas, era estratégico deixar rivalidades de lado e buscar o apoio de outras agremiações, como se deu no caso da fusão entre o Alvorada, da Vila Oeste, e o Vila Rica, do Nova Gameleira.

Períodos de atuação mais liberal do estado ou de distensão de formas autoritárias são sempre mais propí-

\footnotetext{
${ }^{62}$ Essa afirmação pode ser balizada, por exemplo, pela avaliação do cenário atual das agremiações que mantêm atividades por mais de cinquenta anos na cidade. Das quarenta e seis entidades com essa longevidade identificadas pelo "Inventário do Futebol Amador em Belo Horizonte", $80 \%$ possuem campo próprio, apenas $20 \%$ persistem sem um espaço de jogo que administram. Nessa medida, a manutenção de um local para o desenvolvimento das atividades tem estreita relação com a sobrevivência das agremiações.

${ }^{63}$ Prática semelhante era identificada no caso paulistano, com a ocupação de terras destinadas a futuras edificações por clubes de futebol de várzea em acordo com as construtoras. Cf. SCHIFNAGEL, 1979.
} 
cios ao desenvolvimento de alternativas de atuação do associativismo comunitário. Contudo, casos como o dos clubes de futebol de várzea de Belo Horizonte ajudam a pensar sobre a maleabilidade das formas de ação popular, atentando para a necessidade de não limitar as explicações aos condicionantes mais estruturais. Ainda que, em certa medida, eles possam ser definidores dos grandes movimentos, sempre há margem para que outras estratégias possam ser criadas e colocadas em prática.

Ao observar-se a trajetória das agremiações varzeanas em sua luta para garantia de um campo de jogo, pode-se perceber como a definição das configurações e dos usos do espaço urbano, longe de seguir trajetória linear, insere-se em imbricadas negociações que, ainda que assimétricas, podem ter destinos muito diferentes dos imaginados por seus idealizadores. Frente aos mecanismos de controle, por inúmeras vezes, constituemse novas estratégias de resistência e de sobrevivência. Essas, mesmo que invisíveis a olhares mais desatentos, jogam seu papel no desenho do tecido da cidade. O que, para percepções apressadas, é só mais uma anomalia do crescimento desordenado, para aqueles que foram responsáveis pela intervenção tratam-se de importantes lugares de memória, a relembrá-los que algumas vitórias, ainda que pequenas, são possíveis.

\section{Referências}

CHALHOUB, Sidney. Trabalho, lar e botequim. O cotidiano dos trabalhadores no Rio de Janeiro da Belle Époque. São Paulo: Brasiliense, 1986.

DECCA, Maria Auxiliadora Guzzo. A vida fora das fábricas. Cotidiano operário em São Paulo, 1920-1934. Rio de Janeiro: Paz e Terra, 1987.

DOIMO, Ana Maria. A vez e a voz do popular: movimentos sociais e participação política no Brasil pós-70. Rio de Janeiro: Relume-Dumará: ANPOCS, 1995.

DUARTE, Adriano e FONTES, Paulo. "O populismo visto da periferia: adhemarismo e janismo nos bairros da Mooca e São Miguel Paulista (1947-1953)”. Cadernos AEL, v. 11, n. 20/21, 2004.

FONTES, Paulo. Futebol de várzea and the working class - amateur football clubs in São Paulo, 1940s - 1960s. In: FONTES, Paulo; HOLLANDA, Bernardo Buarque de (Org.). The Country of Football: Politics, Popular Culture, and the Beautiful Game in Brazil. Londres: Hurst Publishers, 2014, p. 87-101.

HALL, Peter. Cidades do Amanhã: uma história intelectual do planejamento e do projeto urbanos no século XX. São Paulo: Perspectiva, 1988.

HOLSTON, James. Cidadania Insurgente: disjunções da democracia e da modernidade no Brasil. São Paulo: Cia. Das Letras, 2013.

LAGE, Marcus Vinícius Costa. A política de esportes varguista (1930-1945) e a interação entre os poderes públicos municipal/estadual e os clubes de futebol de Belo Horizonte/MG: permanências e rupturas (?). Temporalidades - Revista Discente do Programa de Pós-Graduação em História da UFMG. v. 7 (Suplemento, 2015) - Belo Horizonte: Departamento de História, FAFICH/UFMG, 2016.

LAVALLE, Adrian Gurza; CASTELLO, Graziella e BICHIR, Renata. "Movimentos sociais e articuladoras no associativismo do século XXI" In: KOWARICK, Lúcio e MARQUES, Eduardo (orgs.). São Paulo: novos percursos e atores: sociedade, cultura e política. São Paulo: Editora 34, 2011. 
LINHALES, Meily Assbú. A trajetória política do esporte no Brasil: interesses envolvidos, setores excluídos. 1996. 242 f. Dissertação (Mestrado) - Faculdade de Filosofia e Ciências Humanas, Universidade Federal de Minas Gerais, 1996.

OLIVEIRA, Samuel Silva Rodrigues de. O movimento de favelas de Belo Horizonte (1959-1964). Rio de Janeiro: e-papers, 2010.

. Trabalhadores favelados."o processo de identificação das favelas e os movimentos sociais no Rio de Janeiro e em Belo Horizonte. 2014. 331 f. Tese (Doutorado) - CPDOC, Fundação Getúlio Vargas, 2014.

PAOLI, Maria Celia. "Os trabalhadores urbanos na fala dos outros. Tempo, espaço e classe na história operária brasileira” In: LOPES, José Sérgio Leite. Cultura e identidade operária: aspectos da cultura da classe trabalhadora. São Paulo: Marco Zero, 1987.

PAOLI, Maria Célia; SADER, Eder \& TELLES, Vera Silva. "Pensando a classe operária: os trabalhadores sujeitos ao imaginário acadêmico". Revista Brasileira de História, Vol. 3, n. 6, 1983.

RAGO, Margareth. Do Cabaré ao lar. A utopia da cidade disciplinar. Brasil, 1890-1930. Rio de Janeiro: Paz e Terra, 1985.

RYKWERT, Joseph. A Sedução do Lugar: a história e o futuro da cidade. São Paulo: Martins Fontes, 2004.

SADER, Eder. Quando novos personagens entraram em cena. Experiências e lutas dos trabalhadores da Grande São Paulo 1970-1980. Rio de Janeiro: Paz e Terra, 1988.

SCHIFNAGEL, Betty. Caracterização geral do futebol de várzea como atividade popular de lazer. Centro de Estudos Rurais e Urbanos/USP, n 12, 1979, p. 110-122.

SPAGGIARI, Enrico. Família joga bola: Constituição de jovens futebolistas na várzea paulistana. $2015.470 \mathrm{f}$. Tese (Doutorado) - Faculdade de Filosofia, Letras e Ciências Humanas, Universidade de São Paulo, 2015.

WEFFORT, Francisco. "Origens do sindicalismo populista no Brasil (A conjuntura do após-guerra)". Estudos Cebrap, 1973.

WEINSTEIN, Barbara. (Re)Formação da Classe Trabalhadora no Brasil (1920 - 1964). São Paulo: Cortez, 2000.

Submissão: 30/09/2017

Aceite: $24 / 02 / 2018$ 